\title{
Local y global: el Estado frente al delito transnacional
}

\section{Local and Global: the State against transnational crime}

RESUMEN

El crimen organizado transnacional (Сот) es una de las principales afectaciones a los Estados nación en el mundo contemporáneo, a tal punto que en muchas ocasiones las redes criminales superan la capacidad de las instituciones. El objetivo de este artículo es evidenciar los límites jurídicos del Estado nación frente a dicho fenómeno desde un análisis histórico-hermenéutico. Esta investigación de tipo cualitativo tiene un nivel interpretativo y se desarrolla a partir de una perspectiva dual, tomando elementos del institucionalismo propio de la Ciencia Política y del análisis del Derecho Internacional y el Derecho Penal. Se sostiene la idea de que el Estado nación puede superar su crisis en la medida que se reconozca una soberanía fragmentada que permita no sólo la hibridación del derecho, sino la hibridación de las instituciones y funciones estatales en materia de seguridad y persecución del delito transnacional. Es decir, los Estados deben migrar a una operatividad en red, tal y como lo hacen los grupos asociados al crimen organizado transnacional.

\section{PALABRAS CLAVES}

Estado nación, criminalidad, soberanía, Derecho Internacional, Derecho Penal.

\section{ABSTRACT}

Transnational organized crime (сот) is one of the main affectations to nation states in the contemporary world, to such an extent that in many occasions

Politólogo de la Universidad Pontificia Bolivariana, Magíster en Seguridad y Defensa de la Escuela Superior de Guerra y Doctor Cum Laude en Derecho Internacional por la Universidad Alfonso X El Sabio. Profesor de Tiempo Completo de la Facultad de Ciencias Sociales y Humanas de la Universidad de Medellín y miembro del grupo de investigación en Conflicto y Paz de la misma universidad. Colombia. Correo electrónico: ppiedrahita@ udem.edu.co

Recibido el 11 de abril del 2018, aprobado el 28 de enero del 2020.

Para citar el artículo: Piedrahita Bustamante P. Local y global: el Estado frente al delito transnacional. En Revista Derecho del Estado, Universidad Externado de Colombia. N. ${ }^{\circ} 46$, mayo-agosto de 2020, pp. 137-160.

DOI: https://doi.org/10.18601/01229893.n46.06 
criminal networks exceed the capacity of institutions. The objective of this article is to show the legal limits of the nation state against this phenomenon from a historical-hermeneutical analysis. This qualitative research has an interpretative level and is developed from a dual perspective, taking elements of the institutionalism proper to political science and the analysis of international law and criminal law. The idea is sustained that the nation state can overcome its crisis as long as it recognizes a fragmented sovereignty that allows not only the hybridization of the law, but also the hybridization of state institutions and functions in terms of security and prosecution of transnational crime. That is, the States must migrate to a network operation, as do the groups associated with transnational organized crime.

\section{KEYWORDS}

Nation state, criminality, sovereignty, international law, criminal law.

\section{SUMARIO}

Introducción. 1. Caracterización del crimen organizado transnacional. 2. El Derecho Internacional frente al crimen organizado transnacional. 3. Salidas políticas y jurídicas al problema. Conclusiones. Referencias.

\section{INTRODUCCIÓN}

Este artículo es un producto del proceso de investigación doctoral ${ }^{1}$ del autor, la cual tuvo como objeto de estudio la crisis ${ }^{2}$ del Estado nación ${ }^{3}$ a partir del crimen organizado transnacional, fenómeno que parte del proceso de globa-

1 PIEDRAHITA, P. El crimen organizado transnacional como crisis del estado nación, 2017. [http://purl.org/dc/dcmitype/Text, Universidad Alfonso X el Sabio]. https://dialnet.unirioja.es/ servlet/tesis?codigo $=219767$

2 Según Jacques Chevallier el Estado nación pasa por una serie de transformaciones que cuestionan los principios sobre los cuales se cimentó a partir de la paz de Westfalia de 1648: la institucionalización del poder, la ciudadanía, el monopolio de la fuerza, las fronteras, la soberanía, la unidad de valores, la unidad del derecho estatal y el orden. En Chevallier, J. El Estado posmoderno. Bogotá: Universidad Externado de Colombia, 2011,p. 19.

3 Según Max Weber el "Estado es una comunidad humana dentro de los límites de un territorio establecido, ya que este es un elemento que lo distingue, la cual reclama para ella -con el triunfo asegurado- el monopolio de la legítima violencia física" en WEBER, M. El Político y el Científico. México: Ediciones Coyoacán, 2010,10. En este sentido, el Estado se caracteriza como una forma de organización política moderna que resultó de la conjugación de varios elementos como: la nación, la figura abstracta, la sociedad, el monopolio de la fuerza y las burocracias. La figura de la nación está asociada al territorio, haciendo del Estado la expresión de una colectividad, un grupo humano, en un territorio específico. En este orden de ideas, el Estado nación es el Estado moderno, aquel aferrado a la concepción tradicional del territorio y el monopolio de la fuerza. Ibid., pp. 13-35. 
lización. El propósito es evidenciar los límites jurídicos del Estado nación en crisis frente al fenómeno del crimen organizado transnacional (en adelante СОт), a pesar de la existencia de diversos instrumentos político-jurídicos del Derecho Internacional como tratados y convenciones. En pocas palabras, se busca comprender la manifestación jurídica y política de dicha crisis y proponer algunas salidas al problema.

El primer acercamiento con la crisis ${ }^{4}$ del Estado nación fue empírica, pero posteriormente fue reforzada a partir de lecturas de teóricos como Manuel Castells, quien desde la década de 1990 afirmó que el control de los Estados sobre el espacio y el tiempo se ha visto superado por los diferentes flujos globales de capital, bienes, servicios, tecnología, comunicación y poder. Paradójicamente las respuestas de los Estados nación a su crisis, siguen una doble vía de resistencia y flexibilización de su soberanía (como ocurre en el espacio europeo). De este modo, se observó cómo las capacidades propias del Estado nación a partir de la paz de Westfalia de 1648, que fueron el punto de partida del moderno sistema internacional (con las interacciones entre países) ${ }^{5}$, la aparición de la figura de los jefes de Estado, las estructuras, instituciones y el concepto de soberanía entendido como el espacio donde se ejerce el poder político y jurídico, se agrietaron y en el mundo contemporáneo han quedado cuestionadas.

Así pues, los acontecimientos de la globalización económica desarticularon lentamente los componentes del Estado; la soberanía dejó de ser una realidad política y de gobierno efectivo en todos los territorios y en las esferas doméstica e internacional. $\mathrm{Y}$ es en este punto donde se unen las manifestaciones jurídicas y políticas de dicha crisis. Por un lado, los Estados nación basados en el "centralismo jurídico", tal como lo plantea Boaventura de Sousa Santos, terminan auto limitándose a partir de una escala espacio temporal que se ha impuesto durante los últimos doscientos años y que configuró una concepción político-ideológica que convirtió al Estado en la única y exclusiva fuente de derecho ${ }^{6}$. Es decir, la concepción jurídica del Estado moderno limita su accionar doméstico e internacional cuando no reconoce las correlaciones espacio temporales entre las escalas nacional y global.

4 En general la crisis del Estado nación ha sido abordada desde la mitad del siglo xx desde diferentes disciplinas que analizaban los efectos de los cambios de los modelos de producción, los cambios de regímenes políticos, la globalización, los cambios de paradigmas de las relaciones internacionales e incluso el terrorismo. Según Chevallier la crisis del Estado nación se ha abordado desde tres perspectivas: una, que contiene la crisis de las representaciones donde se analizaban los desajustes económicos y opresivos del Estado, y las crisis políticas del ultraliberalismo de Tatcher y Reagan; la segunda, desde los totalitarismo; y, la tercer perspectiva, con las crisis de los países en vías de desarrollo. Ibíd., pp. 45-46.

5 Tilly, Ch. Coerción, capital y los Estados Europeos 990-1990. Madrid: Alianza Editorial, 1992.

6 De Sousa Santos, B. Sociología jurídica crítica. Para un nuevo sentido común en el derecho. Bogotá: Instituto Latinoamericano de Servicios Legales Alternativos, 2009, p. 59. 
El problema entonces es que el Estado nación en crisis se concibe en una dimensión territorial, una escala nacional, mientras que se debe enfrentar a problemas de escala global. Si se analiza el contexto internacional sucede algo similar: el sistema occidental está compuesto por un orden jurídico basado en la concepción tradicional del Estado donde priman los conceptos de territorio y soberanía. De tal forma, los ordenamientos jurídicos del sistema internacional occidental presentan limitantes al momento de correlacionarse, pues esto podría implicar ahondar la crisis. Es por esto que, en términos del Derecho Internacional, los tratados y convenciones están marcados por la "buena voluntad" de las partes contratantes, asunto que termina desconociendo la necesaria "plasticidad del derecho estatal moderno" de articulación entre los diferentes ordenamientos jurídicos nacionales para enfrentar una amenaza transnacional.

El artículo se desarrolla bajo un enfoque cualitativo de tipo históricohermenéutico desde el cual se analizan los instrumentos jurídicos para la sanción del сот desarrollados en el marco institucional de las relaciones internacionales; en particular, se hace énfasis en la Convención de Palermo. Con esto, se evidencia que existen los elementos jurídicos que incluyen la información sobre las distintas redes y su enfoque. Sin embargo, parece quedar un vacío al momento de encontrar soluciones a las implicaciones del delito transnacional; existen formas para su combate, pero son formas territoriales marcadas por la jurisdicción y la competencia.

Se sostiene la idea de que el Estado nación puede superar su crisis en la medida que se reconozca una soberanía fragmentada que permita no sólo la hibridación del derecho, sino la hibridación de las instituciones y funciones estatales en materia de seguridad y persecución del delito transnacional. Es decir, los Estados deben migrar a una operatividad en red, tal y como lo hacen los grupos asociados al сот. Un Estado jerárquico, vertical, nacional, aunque tenga las herramientas jurídicas, no posee la capacidad para enfrentar las redes del crimen global. Una idea de este tipo exige desarrollos legislativos y procesales; aquí solo se pretende establecer una salida política y jurídica que deberá tomar forma al interior de cada país y ser discutida en los espacios del orden internacional institucional.

Esta investigación de tipo cualitativo tiene un nivel interpretativo y se desarrolla a partir de una perspectiva dual, tomando elementos del institucionalismo propio de la Ciencia Política y del análisis del Derecho Internacional y el Derecho Penal. En la primera parte se caracteriza el crimen organizado transnacional y los diferentes delitos que contiene más allá del narcotráfico; en la segunda, se analiza el principal instrumento jurídico-político del Derecho Internacional que pretende dar una respuesta al delito transnacional; en 
la tercera, se proponen algunas salidas al problema. Finalmente se concluye que la lógica territorial del Estado seguirá profundizando su crisis mientras las redes del crimen transnacional se hacen más dinámicas y aprovechan los vacíos jurídicos.

\section{CARACTERIZACIÓN DEL CRIMEN ORGANIZADO TRANSNACIONAL}

Históricamente se ha reconocido la importancia de estudiar el fenómeno criminal y en especial, desde la sociología, se han realizado significativos aportes a la materia. Empero, en el mundo contemporáneo los aportes desde la academia siguen siendo escasos al momento de formular las bases para un entendimiento de la conformación y estructura del crimen organizado en el orden mundial de posguerra fría. En esta perspectiva, afirma Manuel Castells que:

Existe un reconocimiento general de la importancia y realidad de este fenómeno, que están atestiguadas por abundantes datos, principalmente de informes periodísticos bien documentados y de las conferencias de las organizaciones internacionales, No obstante, los sociólogos prescinden en buena medida del fenómeno cuando se trata de comprender economías y sociedades, con el argumento de que los datos no son verdaderamente fiables y que adolecen de sensacionalismo. No estoy de acuerdo con estos planteamientos. Si se reconoce un fenómeno como una dimensión fundamental de nuestras sociedades, e incluso del nuevo sistema globalizado, debemos utilizar cualquier dato disponible para explorar la conexión entre estas actividades criminales y las sociedades y economías en general ${ }^{8}$.

A pesar del vacío en el estudio sistemático del cot, existen suficientes elementos para empezar a llenarlo. Pero antes, es necesario abordar una problemática que surge del entendimiento del concepto de "crimen organizado" donde se ha evidenciado que no existe en la academia y en los organismos internacionales un consenso. Algunas características que permiten establecer una noción inicial sobre este son: primero, actividades consideradas como delitos o transgresiones al ordenamiento jurídico y legal de los Estados y desarrolladas por personas con un plan dirigido a obtener un beneficio. Segundo, funciona como la gran empresa contemporánea, incluyendo una estructura de trabajo jerarquizada ${ }^{9}$, con una estricta división del trabajo regida por reglas claras, disciplina interna y manejo de los diferentes asuntos, bien en forma de red o de células dotadas de autonomía y manejo autárquico de la información. Tercero, realización de ejercicios constantes de intimidación

8 Castells, M. La era de la información: economía sociedad y cultura. Vol.III: Fin del Milenio. México: Siglo XII de España Editores, 2006, pp. 200-201.

9 Esta característica se transformó en la segunda mitad del siglo xx cuando ya se puede empezar a describir la transnacionalidad del crimen organizado. 
violenta. Cuarto, influye y corrompe a funcionarios de gobiernos o líderes de opinión de los países. Y, quinto, el crimen organizado es una actividad no ideológica, es decir, no posee fines políticos, sino meramente económicos y de protección a las estructuras criminale ${ }^{10}$. Con esta claridad es necesario abordar la internacionalización del crimen organizado que de acuerdo con Knepper ${ }^{11}$ se originó en la segunda mitad del siglo XIX a partir de la expansión del comercio mundial, el imperialismo europeo, la urbanización, las migraciones masivas y los desarrollos tecnológicos ${ }^{12}$.

Por otra parte, es necesario comprender por qué el crimen organizado adquiere capacidades transnacionales. Para esto es necesario analizar dos referentes históricos y precisar algunos planteamientos que realizó Piedrahita ${ }^{13}$ en su momento. Los elementos que hacen del crimen organizado un asunto "transnacional", son: primero, que se insertó en un nuevo paradigma tecnológico que cambió el alcance y las dinámicas de la economía industrial, fundando una economía globalizada que compite entre diversos actores donde el Estado es parte y no totalidad, asimismo creando una destrucción de grandes partes de la economía que afectó a las regiones, empresas y países ${ }^{14} ;$ y, segundo, porque el crimen organizado entró a la dinámicas de la economía informacional/global, incorporando el conocimiento y la información en la circulación de capitales para no correr el riesgo de desaparecer ${ }^{15}$.

Los efectos de esta "transnacionalidad", pueden rastrearse en el período entre 1987 a 1993 que coincidió con la disolución de la Unión de Repúblicas Socialistas Soviéticas (URSS) y con el proceso de democratización acelerada en Rusia en la década de 1990; y con el proceso de globalización de la información y las comunicaciones. Otro importante antecedente es precisamente que el giro en el paradigma económico que se señaló se dio a comienzos de $1970^{[16-17]}$.

10 Chават, J. (2010). El Estado y el crimen organizado trasnacional: amenaza global, respuestas nacionales. Istor: Revista de historia internacional (42), 3-14, $2010,5$.

11 Citado en СНАВАт, J. (2010). El Estado y el crimen organizado trasnacional: amenaza global, respuestas nacionales. Istor: Revista de historia internacional (42), 3-14, 1.

12 En este punto, el crimen organizado todavía estaba limitado a las fronteras nacionales, pero empezaba a manifestar algunos contactos para la distribución de drogas y productos de contrabando en el ámbito internacional. Aunque es un antecedente que se debe considerar, no guarda relación con lo que se observa en la actualidad, donde el crimen opera en red.

13 Piedrahíta, P. Las redes del crimen global y su impacto en Colombia. Analecta Política, 4 (6), 121-141, 2014.

14 Castells, M. La era de la información: economía, sociedad y cultura. Vol. I: La Sociedad Red. México: Siglo xxI, 2006, p. 118.

15 Ibíd.,p. 119.

16 Ibíd., p. 100.

17 Al respecto, revisar el capítulo 2 de Castells (2006). "La economía informacional y el proceso de globalización" del libro La Era de la Información: economía, sociedad y cultura. Vol. I: La Sociedad Red. Allí el autor analiza las variaciones de la productividad en el mundo e identifica los cambios en la economía a partir de 1970 con la introducción de diferentes cambios 
Según Castells, la consolidación de este nuevo sistema productivo se da en 1990 por lo que la sociedad, los Estados y las empresas apenas tuvieron un momento para procesar tantos cambios. Con todo, los grandes efectos de este paradigma se observan en el nuevo milenio. Justo en este contexto, sucedió un hecho de trascendencia criminal en el marco de la Guerra de Afganistán a finales de 1970 y principios de 1980, cuando la Central de Inteligencia Americana (CIA por sus siglas en inglés) desarrolló un programa secreto denominado sOVMAT para apoyar a los muyahidines afganos en su lucha contra la URSS. Esta operación pasó desapercibida para muchos, pero significó la configuración de una compleja red criminal para su objetivo. Todo consistió en la creación de una serie de empresas fachada que utilizó Estados Unidos para comprar armas soviéticas a diversos países del Pacto de Varsovia y que luego fueron entregadas a los muyahidines. Las armas fueron, posteriormente, utilizadas por Osama Bin Laden para generar toda una privatización de la guerra y luego, el fortalecimiento del terrorismo ${ }^{18}$.

Siguiendo con el argumento principal, la disolución de la URss junto con la incontrolada transición a la democracia en Rusia - que pasó de una economía centralizada, a una de libre mercado - , creó las condiciones necesarias para que grupos criminales que operaban de tiempo atrás, se adaptaran e identificaran los vacíos para insertarse en la economía global a través de diferentes negocios criminales. Al respecto señala Castells que esta transición estimuló:

la proliferación de actividades criminales originadas dentro y fuera de Rusia y la antigua Unión Soviética, como el tráfico ilegal de armas, material nuclear, metales raros, petróleo, recursos naturales y divisas. Las organizaciones criminales internacionales se vincularon con los cientos de redes de mafias postsoviéticas (...), para blanquear dinero, adquirir propiedades valiosas y hacerse con el control de negocios ilegales y legales prósperos ${ }^{19}$.

A partir de lo ocurrido en Rusia, se crearon alianzas estratégicas de colaboración entre los diferentes criminales en el mundo, como: grupos armados ilegales; las mafias italianas; redes criminales asiáticas, del medio oriente y los Estados Unidos que, en lugar de enfrentarse, o disputar los réditos ilegales, aprovecharon el nuevo escenario global para su expansión y configuración de redes por todo el mundo. De esta forma el cot se consolidó como una amenaza

tecnológicos. Allí evidencia cómo la productividad en el mundo cae considerablemente con estos cambios, pero para entender este efecto afirma que los nuevos descubrimientos tecnológicos necesitan de un intervalo de tiempo considerable entre la innovación tecnológica y la productividad económica (p. 102).

18 VeIGA, F. El desequilibrio como orden. Una historia de la posguerra fría 1990-2008. Madrid: Alianza, 2009, pp. 328-329.

19 Castells, M. La era de la información: economía sociedad y cultura. Vol.III: Fin del Milenio. México: Siglo XII de España Editores, 2006, p. 214. 
de escala global que, por lo general, desarrolla una estrategia consistente en ubicar sus funciones de gestión y producción en zonas de bajo riesgo, donde sus integrantes poseen un control relativo del territorio, mientras que buscan mercados ricos donde las demandas de productos ilícitos son mayores ${ }^{20}{ }^{21}$.

La globalización de la información apoyada en la tecnología generó la apertura de las fronteras de los Estados para propiciar el libre mercado, el fácil tránsito en tiempo real de la economía, la movilidad de los capitales por todo el mundo y el intercambio de información y conocimiento. Esto significó la consolidación de grupos delincuenciales que, al tomar provecho del fenómeno de la globalización, expandieron sus acciones tomando un carácter transnacional. De igual modo, la globalización ha sido considerada una transformación para el desarrollo de las sociedades, pero también ha distinguido la existencia de nuevas amenazas para la seguridad global, porque las instituciones encargadas de la seguridad en los Estados no se han fortalecido con el fin de controlar fronteras en un mundo abierto y disperso ${ }^{22}$. En consecuencia, Blanco y Sánchez afirman que

el fenómeno de la globalización de los mercados, de la demanda de productos ilegales y del sistema financiero, es el elemento clave que ha atraído a las organizaciones criminales a superar el marco nacional y a realizar actividades a nivel internacional o transnacional ${ }^{23}$.

Frente a esto, el profesor Herfried Münkler diferenció entre la globalización de los mercados como fenómeno positivo para el desarrollo, de lo que denomina la "globalización en la sombra", que es la utilizada por grupos armados ilegales en el mundo, para vincularse a los beneficios de la economía legal

20 Ibíd., 201.

21 "Los dineros, producto de la realización de transacciones de los diferentes negocios criminales, entren al sistema financiero presupone un gran reto para un Estado nación en crisis, dejando secuelas importantes como son: en primer lugar, la posibilidad de que a raíz de la amplia circulación de dinero sin control las instituciones de los Estados sean penetradas y viciadas, asunto que se ve reflejado especialmente en temas de corrupción, amenazas y financiamiento político que terminan degenerando el mandato de los asuntos públicos" (CASTELLs, 2004, p. 289); en segundo lugar, lleva a que las agendas de los Estados giren en torno a la ayuda y asistencia para hacer frente a la criminalidad global; y en tercer lugar, los dineros negros que entran al sistema "son elementos claves para estimular o desestabilizar economías nacionales enteras" Piedrahíta, Las redes del crimen global y su impacto en Colombia, 2014, p. 126.

22 Konrad Adenauer. Seguridad y crimen organizado transnacional. Guatemala: Serviprensa, 2011, p. 17.

23 Blanco, I., y SÁnchez, I. (s.f.). Principales instrumentos internacionales (de Naciones Unidas y la Unión Europea) relativos al crimen organizado: la definición de la participación en una organización criminal y los problemas de aplicación de la ley penal en el espacio. Revista Penal, 3-14, s.f., 4. 
y así extraer los recursos necesarios para su mantenimiento ${ }^{24}$. La globalización en la sombra se sustenta en el hecho de que la economía ha adquirido la capacidad de funcionar en tiempo real y a escala global.

Este proceso, según Blanco y Sánchez, ofreció unas ventajas para el crimen organizado, como: uno, el acceso a mercados de bienes ilícitos lucrativos; dos, la introducción a los sectores e instituciones de Estados débiles o democracias en construcción; tres, la capacidad de actuar en lugares seguros como, por ejemplo, países que no penalizan ciertas conductas ilegales, manteniéndose por fuera de la órbita de los organismos de seguridad; cuatro, la canalización de réditos económicos a través del sistema financiero global, que en ocasiones no posee los controles necesarios para el seguimiento de actividades ilegales; y, cinco, el acceso a los países considerados como "paraísos fiscales", donde se realizan actividades de blanqueo de dineros, para luego retornarlos a los lugares de operación criminal de forma legal ${ }^{25}$. Según Zaffaroni, estas situaciones afectan a los Estados a través de problemas como la corrupción institucional y la desviación hacia lo ilícito que arruinan las economías nacionales y limitan las acciones jurídicas y de seguridad de los Estados ${ }^{26}$.

Los Estados en crisis deben enfrentar este complejo fenómeno que "cada día toma mayor dinamismo, con un rápido aumento en su nivel de peligrosidad, multiplicando su capacidad de acción y, por ende, el daño que ocasiona a la sociedad" ${ }^{27}$. Es así como la transnacionalidad como carácter específico de la criminalidad presenta unas dinámicas asociadas a la erosión de la soberanía, generando "Estados frágiles" como los denomina Manuela Mesa ${ }^{28}$ debido a su interdependencia globalizada que ha contribuido a la desigual distribución de la riqueza, acentuando la polarización económica. Si la globalización ha tenido estos efectos corrosivos sobre la economía de los ciudadanos, la criminalidad transnacional al operar de acuerdo con su dinámica contribuye en gran medida a consolidar esta situación.

La operación transnacional está estrechamente relacionada con el movimiento financiero que beneficia por igual a los capitales lícitos e ilícitos y a estos últimos les facilita su operatividad y anonimato. Para garantizar ese ocultamiento, la dinámica más corriente consiste en el bloqueo de los controles,

24 MüNKLER, H. Viejas y nuevas guerras. Asimetría y privatización de la violencia. (C. Ramírez, Trad.) Madrid: Siglo XII de España Editores, 2005, p. 13.

25 Blanco, I., y SÁncheZ, I. Principales instrumentos internacionales (de Naciones Unidas y la Unión Europea) relativos al crimen organizado: la definición de la participación en una organización criminal y los problemas de aplicación de la ley penal en el espacio. Revista Penal, 3-14, s.f., 4-5.

26 ZAFFARONI, R. Globalización y crimen organizado. Voces para la libertad. Reflexiones sobre la represión (pp. 261-286). Guadalajara: Universidad Autónoma Metropolitana, 2007, p. 263.

27 KonRAd AdENAUER. Seguridad y crimen organizado transnacional. Guatemala: Serviprensa, 2011, p. 17.

28 Mesa, M. Paz y conflictos en el siglo XXI: tendencias globales. Madrid: Icaria, 2007. 
acudiendo a todo tipo de actuaciones y generando (a veces aprovechando) "vacíos de poder" en zonas económicas o en localidades donde no puedan acceder las autoridades e inclusive silenciándolas, a través de la violencia. Frente a esto, Castells ${ }^{29}$ señala cómo la globalización ha acentuado la pobreza de muchos, ha incrementado la opulencia, creando divisiones muchos más tajantes que las existentes antes ${ }^{30}$. Y esta división social no solo favorece las actividades ilegales, sino que además impide un verdadero desarrollo democrático, el ejercicio de la ciudadanía, la participación política y el verdadero disfrute de los derechos políticos. Es decir, que no solo son efectos económicos los que pesan sobre la sociedad cuando abundan los capitales de actividades ilegales, sino que también son las consecuencias políticas y sociales que sufren los Estados.

Estas dinámicas que debilitan el Estado nación le impiden ejercer el control sobre poblaciones y resolver conflictos. De este modo, el Estado pierde la capacidad de gobernar su territorio y en este contexto de anomia no hay capacidad para garantizar la seguridad de los ciudadanos, ni ofrecer bienes públicos como educación, salud y bienestar, además de no poder hacer uso del monopolio de la fuerza. En estos Estados débiles las redes funcionan de forma libre. Por ejemplo, Haití es uno de esos casos, pero también Colombia, en donde señala Mesa que la situación de gobernabilidad ha sido erosionada por fuerzas que como las autodefensas ilegales (AUC) tenían actividades transnacionales de droga y habían cooptado en un $30 \%$ el órgano legislativo ${ }^{31}$. Sin embargo, lo paradójico es que las redes del crimen transnacional funcionan también en aquellos Estados fuertes como en Europa y Estados Unidos ${ }^{32}$.

Otra dinámica está asociada a la presencia de armas personales pequeñas y ligeras, que sustituyen en muchos casos el monopolio de la violencia y de las armas que debe regir en todo Estado moderno. La sensación y la percepción de inseguridad derivada de la no-gobernabilidad y de la ineficacia de las fuerzas del Estado cooptadas o desplazadas, es aliviada mediante la posesión y el uso de las armas que generan el aumento de la violencia por la falta de la concentración por parte de las autoridades estatales.

Todas estas situaciones exigen respuestas de las autoridades. Se considera que el ideal sería que las respuestas lograran la disminución de todas las formas de violencia, combatir la exclusión, fortalecer la acción de los organismos de seguridad, fortalecer las instituciones estatales más allá de

29 Castells, M. La Era de la Información: economía, sociedad y cultura. Vol. I: La Sociedad Red. México: Siglo XxI, 2006.

30 Mesa, M. (2007). Paz y conflictos en el siglo XxI: tendencias globales. Madrid: Icaria, 2006, p. 41.

31 Piedrahita, P. Las redes del crimen global y su impacto en Colombia. Analecta Política, 4 (6), 2014, 121-141.

32 Al respecto, ver Glenny, M. (2009). McMafia: El crimen sin fronteras. Barcelona: Destino. 
la verticalidad. Sin embargo, predomina el enfoque criminal apoyado en el ámbito del orden internacional occidental institucional. Es decir, las respuestas jurídicas de los Estados frente al fenómeno descrito están ceñidas a los conceptos de soberanía, territorio, competencia y jurisdicción; a la existencia de un derecho de escala nacional y un Derecho Internacional limitado y condicionado por este. El resultado, como se analiza en el siguiente punto es que desde el Derecho Internacional existen instrumentos jurídicos que pretenden solucionar el problema, pero que al momento de ser aplicados no superan la escala nacional.

\section{EL DERECHO INTERNACIONAL FRENTE AL CRIMEN ORGANIZADO TRANSNACIONAL}

En este aparte se realiza el análisis hermenéutico de la Convención de las Naciones Unidas contra la Delincuencia Organizada Transnacional, que es el principal instrumento de Derecho Internacional frente al сот. Dicha convención junto a sus protocolos adicionales se conoce usualmente como el "Protocolo de Palermo". Este tratado internacional publicado en noviembre de $2004^{[33]}$ contiene las resoluciones 55/25 (15 de noviembre de 2000), 55/255 (31 de mayo de 2001), el protocolo para prevenir, reprimir y sancionar la trata de personas, especialmente mujeres y niños, el protocolo contra el tráfico ilícito de migrantes por tierra, mar y aire y el protocolo contra la fabricación y el tráfico ilícito de armas de fuego, sus piezas, componentes y municiones.

El contenido de la Convención está marcado por el constante deseo de cooperación para prevenir y combatir más eficazmente el delito transnacio$\mathrm{nal}^{34}$. En este sentido, presenta las definiciones que delimitan este fenómeno en el sistema internacional:

a) Por "grupo delictivo organizado" se entenderá" un grupo estructurado de tres o más personas que exista durante cierto tiempo y que actúe concertadamente con el propósito de cometer uno o más delitos graves o delitos tipificados con arreglo a la presente Convención con miras a obtener, directa o indirectamente, un beneficio económico u otro beneficio de orden material.

Posteriormente, en su ámbito de aplicación, señala las características de la "transnacionalidad del delito": si se comete en más de un Estado o si se comete dentro de un solo Estado, pero su preparación, dirección o efectos involucran a otros Estados o grupos delictivos de otros Estados. Sin embargo, la descripción del delito transnacional está acompañada de la garantía

33 ONu. Convención de las Naciones Unidas contra la Delincuencia Transnacional y sus Protocolos. Nueva York: Organización de Naciones Unidas, 2004.

34 Ibíd., p. 5. 
de protección que tienen todos los Estados parte en su soberanía a través del principio de la no intervención en los asuntos internos. Es decir, existe un reconocimiento de un fenómeno que no reconoce las fronteras mientras que los instrumentos jurídico-políticos funcionan a la inversa.

Los alcances del convenio están definidos por la adopción que los Estados deben realizar de una definición legislativa de lo que es un delito. Asimismo, plantea una serie de medidas y penalizaciones contra el blanqueo de dinero y la corrupción. Con respecto al primero, establece la necesidad de un reglamento de supervisión de bancos e instituciones financieras no bancarias susceptibles de utilizarse para dicho fin, así como la cooperación de los Estados parte para el intercambio de información orientada a detectar el delito; también plantea que los Estados deben tomar medidas para controlar el movimiento transfronterizo. Con respecto a las medidas contra la corrupción, establece la adopción de métodos que garanticen la intervención de las autoridades para detectar y castigar a los funcionarios públicos que incurran en actos de corrupción.

Frente al juicio de responsabilidad a las personas jurídicas, establece el proceso, fallo y sanciones de los actos delictivos, incluyendo asuntos como el decomiso e incautación de bienes producto de la delincuencia y la cooperación internacional para fines de decomiso y la disposición del producto. Para manejar el tema de la soberanía, se instaura la responsabilidad en cabeza de cada Estado, para que se apropie del procesamiento de aquellos que comentan delitos dentro de su territorio, a bordo de un buque o aeronave en su jurisdicción; o contra uno de sus nacionales o contra un Estado parte.

En el caso de la extradición se establecen elementos como los motivos de extradición (distintos a los delitos graves). Aun cuando no haya un tratado de extradición, el Protocolo de Palermo facilita esas solicitudes, sin que esto sea una obligación. También se observa cómo el más importante instrumento de lucha contra el сот reconoce que las medidas frente a un fenómeno transnacional deben ser particulares en cada país.

Finalmente, respecto a la judicialización de los actores de los delitos, la convención propone la asistencia judicial recíproca entre todos los Estados parte, así como la posibilidad de solicitar declaraciones de personas, presentar documentos judiciales, realizar inspecciones e incautaciones, facilitar información y elementos de prueba o cualquier otro tipo de asistencia autorizada por el derecho interno del Estado parte. Se invita además a que los gobiernos realicen acuerdos bilaterales o multilaterales para cooperar en el combate de la delincuencia. Del mismo modo, se contempla la penalización de la obstrucción de la justicia (fuerza física, amenazas o intimidación), la protección de los testigos contra actos de represalias y la asistencia y protección a las víctimas.

En el primer anexo del tratado, se encuentra el protocolo para prevenir, reprimir y sancionar la trata de personas, especialmente mujeres y niños. 
En este se definen todos los conceptos desarrollados y la importancia de la penalización y tipificación del delito, incluyendo la complicidad en el mismo u organizaciones que a ello se dediquen ${ }^{35}$. Posteriormente el protocolo trata la prevención y la cooperación, haciendo énfasis en el establecimiento de políticas, programas y otras medidas que combatan el delito y protejan a las víctimas, cooperando en actividades de investigación o promoviendo medidas legislativas de otra índole (educativa, social o cultural). Respecto a la cooperación en actividades investigativas, se propone especialmente compartir información respecto a la realización de los delitos y sus métodos. Por lo demás, se proponen medidas fronterizas para un mayor control del paso o de la utilización de transportes obligados, así como de los documentos: la seguridad de estos (su calidad e integridad) y su legitimidad. Por último, el protocolo incluye algunos artículos dedicados a la resolución de controversias por medio de la negociación y a la denuncia del Protocolo, así como la posibilidad de una enmienda a este.

En el segundo anexo, se encuentra el protocolo contra el tráfico ilícito de migrantes por tierra, mar y aire, el cual reglamenta los procedimientos de los Estados parte respecto al tráfico de personas. En este texto se establecen las definiciones pertinentes, mecanismos de cooperación y lineamientos de acción en los casos en los que se presente esta dinámica criminal, como: finalidad, definiciones y penalización ${ }^{36}$.

Frente a lo dispuesto en los protocolos anteriores, desde la academia se han realizado diferentes críticas. Se destaca la realizada por la abogada australiana Anne Gallagher ${ }^{37}$ quien plantea que las definiciones de los protocolos no son perfectas, pero son lo suficientemente aproximadas para que puedan contribuir al control del tráfico y el contrabando por parte de los Estados ${ }^{38}$. En el caso de los compromisos o acuerdos, se debate que la mayoría de las prácticas propuestas no son de carácter obligatorio, haciendo deficiente su efectividad en la mayoría de los casos, lo cual implica la vulneración de los derechos de las víctimas o los migrantes y la impunidad para los traficantes. Por otra parte, ninguno de los dos protocolos explica la manera de identificar los migrantes ilegales, por lo que es igualmente complejo garantizar sus derechos, en especial si el tráfico se encuentra asociado al сот, lo cual pondría a la víctima en una mayor posición de vulnerabilidad; ni siquiera se considera la posibilidad de errar en la identificación de los migrantes.

En el último anexo del Convenio de Palermo se encuentra el protocolo contra la fabricación y el tráfico ilícito de armas de fuego, sus piezas, com-

35 Ibíd., pp. 44-45.

36 Ibíd., p. 58.

37 Gallagher, A. Trafficking, smuggling and human rights: tricks and treaties. Forced Migration Review (12), 2002, 25-28.

38 Ibíd., pp. 26-27. 
ponentes y municiones, el cual hace énfasis en la fabricación y tráfico ilícito de armas de fuego ${ }^{39}$. Es necesario precisar, que la referencia a la aplicación que hace el protocolo es sólo respecto a los delitos previamente definidos, y no a las transacciones estatales. Para la prevención de los delitos, se consideran procesos eficientes de registro (a través de las marcas pertinentes y las fechas de emisión y expiración), la marcación de las armas de fuego (en su momento de fabricación con "nombre del fabricante, el país o lugar de fabricación y el número de serie, código numérico y/o alfanumérico") que permita a todas las partes contratantes identificar sin dificultad el país de fabricación ${ }^{40}$ y la desactivación de las armas (de todas las no registradas o debidamente marcadas, tornando todas sus piezas inservibles con verificación de una autoridad competente). Asimismo, la Convención propone la manutención de un sistema de licencias y autorizaciones de exportación e importación, así como de expedición, donde el Estado receptor mantenga constantemente informado al exportador del tránsito y recepción de pedidos.

Por último, el protocolo termina señalando que, para prevenir y combatir la fabricación y tráfico de armas, es necesario establecer un sistema de reglamentación a las actividades relacionadas con el corretaje de licencias, registro de los corredores y la inclusión de datos de estos para facilitar un posterior intercambio de información con el fin de que los Estados fortalezcan su atributo propio del monopolio de la violencia.

La Convención, y sus tres protocolos anexos, es considerada por muchos como una acertada salida contra el сот, en el sentido que, no solo aborda el problema para la seguridad de los Estados., sino que trata de establecer una perspectiva unánime para combatirlo. Sin embargo, como argumentan Zúñi$\mathrm{ga}^{41}$ y Jiméne $\mathrm{z}^{42}$, su régimen solo fija mínimos y deja un vacío al imponer obligaciones a los Estados miembros. Además, la Convención evidencia que es casi imposible encontrar una perspectiva jurídica común desde la cual se pueda abordar la problemática. Al respecto afirma Jiménez:

A la hora de delimitar los tipos delictivos en el artículo 5, la Convención acumula en lugar de optar por una de las dos aproximaciones doctrinales existentes en relación con la delincuencia organizada: el modelo anglosajón de la «conspiración» (art. 5.a.i) y el modelo continental basado en la «asociación» (art. 5.a.ii) (McClean, 2007, p. 62). En definitiva, es una delimitación efectuada a partir no tanto de las características de la organización, sino de las posibles actividades delictivas, las cuales, por si esto fuera poco preciso, se determinarán no por

39 Ibíd.,pp. 74-75.

40 Ibíd.,p. 77.

41 ZuÑGA, L. El concepto de criminalidad organizada transnacional: problemas y propuestas. Nuevo Foro Penal, 12 (86), 62-114, 2016, 67.

42 JIMÉNEZ, C. La lucha de la UE contra el actual crimen organizado: un reto esencial... pero difícil. СІDОв d'Afers Internacionals (111), 35-56, 2015, 39. 
una tipología, sino por un criterio cuantitativo: el de la pena sobre actividades delictivas - delitos con condenas de mínimo cuatro años-, con lo que cabe perfectamente la posibilidad de que unas mismas conductas, dependiendo de los códigos penales de cada Estado, entren o no en la tipología ${ }^{43}$.

Siguiendo en esta línea crítica y frente a la problemática para el derecho, Jiménez advierte que la diferencia semántica entre quienes consideran el crimen organizado como una asociación y quienes lo visualizan como una conspiración afecta la tipicidad, porque en este último no se tiene en cuenta el número de personas que intervienen en la comisión del delito que es precisamente uno de los criterios definitorios de este delito ${ }^{44}$.

\section{SALIDAS POLÍTICAS Y JURÍDICAS AL PROBLEMA}

Además del Protocolo de Palermo, existen muchos más instrumentos del Derecho Internacional referentes a los delitos asociados al $\mathrm{COT}^{45}$. A pesar de esto, en el marco legal es necesario establecer mecanismos de control real y efectivo, enfatizando en la obligación de los Estados en la cooperación y la coordinación operativa, las actividades de análisis conjunto, la evaluación y el control, la transferencia de técnicas y métodos, la formación y el intercambio de expertos, así como las actividades de sensibilización y difusión. En particular, es necesario deconstruir los instrumentos judiciales y los conceptos de jurisdicción y competencia para que efectivamente se sancionen estas conductas. Por esto es por lo que se afirma que la salida política al problema de la crisis del Estado pasa por una necesaria fragmentación de la soberanía. Es necesario que los Estados establezcan mecanismos de soberanía compartida, una hibridación del derecho y de los organismos de seguridad para enfrentar el delito.

Los organismos de seguridad que funcionan como componentes de la aplicación de la justicia no pueden proceder solos, pues sin la acción judicial posterior es inocua su actuación como lo afirma Callegari ${ }^{46}$. Pero tampoco puede descansar todo el peso del control criminal transnacional en las normas, las acciones policiales y el uso del derecho a la fuerza y a la sanción, sino que deben darse otro tipo de acciones estatales y de cooperación real

43 Ibíd., p. 40.

44 Ibíd.,p. 41.

45 En el proceso de investigación doctoral del autor se pudieron establecer cerca de 58 tratados internacionales que tienen por objetivo luchar contra delitos como: armas de fuego (tráfico ilegal), tráfico de mujeres, tráfico de inmigrantes (tráfico de personas), tráfico de oro, metales y piedras preciosas, narcotráfico, productos falsos, tráfico de vida Salvaje, blanqueo de dinero (lavado de activos), extorsión, juegos de azar, daños al medio ambiente y tráfico de órganos.

46 CAllegari, A. Crimen organizado y su tipificación delante del contexto de la expansión del derecho penal. Derecho Penal y Criminología, 31 (91), 15-39, 2010, 146. 
de los Estados para combatir la delincuencia más allá de los lineamientos ideológicos de los gobiernos. Es el Estado como una totalidad el que debe responder al desafío. Las normas internacionales apuntan a ello, pero ¿hasta dónde su proliferación garantiza un control eficaz?, pregunta que adquiere relevancia cuando se constata la enorme cantidad de convenios, acuerdos y tratados existentes en el mundo para combatir la criminalidad. En este orden de ideas, se sostiene que el Estado nación debe pensar una nueva forma de funcionamiento: no vertical; un funcionamiento en red entre Estados. En esta línea está lo planteado por Chevallier, cuando sostiene que en el contexto de la crisis del Estado nación es necesario un nuevo modelo de organización social, teniendo en cuenta que, incluso, la sociedad contemporánea se caracteriza por nuevas figuras de orden o de desorden según la posición que se tome, como: el rizoma, el laberinto o la red ${ }^{47}$.

Ferrajoli citando a Bobbio afirma que "nuestro tiempo de los derechos, es también el tiempo de su más amplia violación y de la más profunda e intolerable desigualdad" 48 . Según este autor, hay una incapacidad del derecho para producir normas a la altura de los desafíos de la globalización, crisis que se manifiesta en el resquebrajamiento de dos de sus funciones de garantía: la prevención de los delitos y la prevención de penas arbitrarias, problema que se desdobla a su vez en dos: la cuestión criminal y la cuestión penal ${ }^{49}$. La cuestión criminal ya se ha descrito en el acápite anterior, sobre sus componentes y sus amenazas a los derechos, a la democracia y al Estado mismo.

En lo que se refiere a la nueva cuestión penal, como la denomina el autor, que responda a los desafíos de la nueva cuestión criminal y a la altura de los desafíos de la globalización, hay que pensar en un sistema de globalización de los sistemas jurídicos que sea análogo al fenómeno ocurrido con el crimen. La adopción de una política en este sentido no podría pasar por lo que Ferrajoli denomina "la inflación del derecho penal" 50 que ha llevado a la quiebra de la maquinaria judicial. Dice sobre el tema:

Asistimos, en todos los países de Occidente, a una crisis de sobreproducción del derecho penal, o incluso del derecho en general, que está provocando el colapso de su capacidad regulativa. Las leyes se cuentan por decenas de millares, hasta el punto de que nuestros ordenamientos han regresado - a causa del caos normativo, de la multiplicación de las fuentes ${ }^{51} \mathrm{y}$ de la superposición de las competencias - a la "incerteza" y la arbitrariedad propia del derecho jurisprudencial premoderno. $\mathrm{Y}$, sin embargo, con aparente paradoja, a la inflación legislativa se corresponde la

47 Chevallier, J. El Estado posmoderno. Bogotá: Universidad Externado de Colombia, 2011, pp. 20-23.

48 FerRAJOLI,L.Criminalidad y globalización.Estudios de Derecho,65(145), 16-29, 2009, 17.

49 Ibíd.,p. 18.

50 Ibíd.,p. 25.

51 La multitud de tratados internacionales y sus protocolos dan cuenta de este problema. 
ausencia de reglas, de límites y de controles sobre los grandes poderes económicos transnacionales y sobre los poderes políticos que los alientan. La globalización, como he dicho, se caracteriza, en el plano jurídico, como un vacío de derecho público dentro del que tienen espacio libre formas de poder neo-absolutista cuya única regla es la ley del más fuerte ${ }^{52}$.

Este análisis del jurista italiano permite fijar dos extremos: si fracasa el ius puniendi (como potestad o poder atribuida a determinados órganos del Estado para imponer penas, sanciones y medidas de seguridad a quienes después de un proceso, también contemplado en la ley, los encuentre responsables de los delitos), a la par que comparte (o renuncia) el monopolio de la violencia con los actores del delito, es el propio Estado el que no solo está en crisis, sino que tiene que replantearse sus funciones y reasumir las que le corresponden.

En parte la denominada explosión legislativa se encuentra con un problema grave que el Derecho Internacional ha debido resolver y que el Derecho Penal Transnacional tiene que plantearse seriamente y es el problema de la tipicidad de las conductas, al que se refiere Zúñiga en los siguientes términos:

(...) la caracterización de la conducta criminal transnacional incluye el hecho de ser varias personas quienes incurren en ella, distribución de tareas, permanencia, actividad internacional, violencia, uso de estructuras comerciales, ánimo de lucro (...). En consecuencia, el elemento punible de la conducta es la participación criminal, tal como lo establece la "Convención de Naciones Unidas contra la Criminalidad Organizada Transnacional” establece que su finalidad es "promover la cooperación para prevenir y combatir más eficazmente" este fenómeno criminal (art. 1). Ello quiere decir que el fin último de este acuerdo internacional es el acercamiento de los países en definir qué es el delito transnacional, toda vez que se trata de un flagelo que requiere de la necesaria cooperación de los Estados. Para ello se requiere una armonización mínima de las legislaciones nacionales, empezando por los conceptos que se encuentran en su base ${ }^{53}$.

El razonamiento de Zúñiga se ciñe a lo establecido en el Protocolo de Palermo, señalando que no considera o no define realmente la criminalidad organizada, ni le asigna sanciones y que solo se refiere al COT, por cuanto la redacción del articulado se refiere al verbo rector "cometer" 54 , objetivo que está lejos de la actividad de la criminalidad organizada como red. Este punto es importante tenerlo en cuenta, porque define la dificultad para combatir las actuales redes criminales, con las herramientas que brinda Palermo. Según Zúñiga existen cuatro supuestos para el enjuiciamiento y castigo del delito transnacional: se

52 Ibíd.,pp. 21-22.

53 ZÚÑIGA, L. El concepto de criminalidad organizada transnacional: problemas y propuestas. Nuevo Foro Penal, 12 (86), 62-114, 2016, 88-89.

54 Ibíd.,p. 92. 
comete en más de un Estado; se comete dentro de un Estado, pero una parte sustancial de su preparación, planificación, dirección o control se realiza en otro; se comete dentro de un solo Estado, pero entraña la participación de una red criminal con operaciones en más de un Estado; y, por último, se comete en un solo Estado, pero tiene efectos esenciales en otro ${ }^{55}$.

Los supuestos contemplados reúnen las características que el concepto criminológico de сот denota: fenómenos criminales que trascienden las fronteras, trasgreden las leyes penales de varios Estados y/o que tengan impacto en otros Estados. En estos casos resultan comprometidas las leyes nacionales de dos o más Estados y, por tanto, tienen trascendencia más allá del límite territorial. La relevancia de estos fenómenos criminales (la dañosidad social), está en causar efectos jurídicos, sociales y económicos en más de un Estado. Al respecto, sostiene Boister que "la delincuencia transnacional describe conductas que tienen efectos transfronterizos reales o potenciales más allá de las fronteras nacionales y puede dar lugar a una preocupación internacional" ${ }^{\prime 6}$. Por esto es necesario que los distintos países que adhieren a la Convención determinen en sus legislaciones internas aquellos delitos que pueden cometerse en diversos países en forma de criminalidad organizada, o afecten los intereses de esos otros países, a fines de que sean conductas eficazmente sancionadas ${ }^{57}$. Esto podría ser un primer acercamiento a una hibridación jurídica.

Por ejemplo, en Colombia el artículo 340 del Código Penal establece el tipo penal de "concierto para delinquir" ${ }^{8}$. Este tipo penal puede descomponerse para identificar la antijuridicidad que, en su fase subjetiva, contempla la existencia de voluntad libre de los partícipes, quienes se asocian voluntariamente en una especie de sociedad para la criminalidad que es lo que determina el concierto. Teniendo en cuenta la existencia de la voluntad, el concierto para delinquir sólo se presenta en la modalidad del dolo, no admitiendo la culpa, como tampoco admite la preterintención ${ }^{59}$. En la fase objetiva, hay que considerar que el mencionado tipo contempla todos los elementos para que la comisión del delito se realice: el verbo rector que define la acción está redactado como "concertarse para delinquir" y debe ser realizado por varias

55 Ibíd.,pp. 93-94.

56 BoIster, N. Transnational Criminal Law? EJIL, 14 (5), 953-976. 2003, 954.

57 ZÚÑIGA, L. El concepto de criminalidad organizada transnacional: problemas y propuestas. Nuevo Foro Penal, 12 (86), 62-114, 2016, 89.

58 ARTícUlo 340. CONCIERTO PARA DELINQUIR. <Artículo modificado por el artículo 8 de la Ley 733 de 2002. Penas aumentadas por el artículo 14 de la Ley 890 de 2004, a partir del 1 o. de enero de 2005. El texto modificado y con penas aumentadas es el siguiente:> Cuando varias personas se concierten con el fin de cometer delitos, cada una de ellas será penada, por esa sola conducta, con prisión de cuarenta y ocho (48) a ciento ocho (108) meses. En Congreso de Colombia. (2000). Código Penal. (44097). Bogotá: Diario Oficial.

59 Alonso, P., y Ruiz, N., Alvarino, J. Apuntes del tipo penal concierto para delinquir en la legislación colombiana. Pensamiento Americano, 2013, 61-69 
personas; siendo así, da lugar a la figura de la pluralidad de autores, de conformidad con el artículo 28 del Código Penal ${ }^{60}$. De tal forma, la normatividad colombiana permite el juzgamiento de los criminales organizados para una actividad delictiva, considerando y juzgando las conductas cometidas en el país o que, siendo cometidas en otro, sus consecuencias se materializan en Colombia. Esta misma línea es la regla general en los Estados modernos.

Haciendo una comparación en el derecho, en el caso de Chile, Matus ${ }^{61}$ trata el tema de la eficacia de la norma, recodando que no existe pena sin delito que la consagre según el principio de derecho "Nullum crimen, nulla poena sine previa lege". Además, afirma que el conjunto de normas que contemplan todos aquellos delitos considerados como cometidos por grupos de criminalidad organizada, imponen obligaciones de implementación de la penalización de determinadas conductas, de acuerdo con el derecho interno de cada Estado $^{62}$. Al respecto, señala:

Una característica del conjunto de convenciones y tratados que regulan los "crímenes de trascendencia internacional" pero que no constituyen "crímenes de derecho penal internacional (como el genocidio) ni son parte de un "derecho penal supranacional"(como los delitos consagrados para la Comunidad Europea), es que sus normas no son "autoejecutables" (self'executing) sino que constituyen obligaciones internacionales de diferente intensidad (según la clasificación de Virally "invitaciones a observar comportamientos", "obligaciones de desarrollo discrecional", "obligaciones generales no concretadas", y "obligaciones concretas"), que en todo caso se encuentran necesitadas de implementación por parte de los Estados suscriptores, conforme a su propio sistema jurídico ${ }^{63}$.

Frente a esta situación, Matus se pregunta cómo aplicar estas normas, de acuerdo con los sistemas penales vigentes, que en su caso es el de Chile, pero que aplica para los sistemas occidentales casi que de manera general. La obligación de implementar las reglamentaciones es ineludible y por ello los tratados y las convenciones recurren a técnicas para obligar a los Estados parte a que informen sobre sus adelantos en la materia. Es lo que sucede con UNODC organismo que provee de:

(...) asistencia legal (incluyendo la elaboración de legislaciones modelos y guías para su implementación), entrenamiento a legisladores, jueces y fiscales, y asesoría técnica para facilitar la colaboración judicial (traducciones, intermediación, etc.)

60 Ibíd.,p. 63.

61 MATus, J. Las formas de responsabilidad criminal por el hecho colectivo en el Derecho Internacional y en el derecho interno chileno. Política Criminal, 8 (16), 2013, pp. 363-385

62 Matus, J. La Política Criminal de los Tratados Internacionales. Ius et Praxis, 13 (1), 2007, 267-289.

63 Ibíd., p. 272. 
con el propósito de hacer efectivos los objetivos de las principales convenciones sobre crímenes de trascendencia internacional ${ }^{64}$.

En este sentido, la Organización de Naciones Unidas (ONU) en el 2004 elaboró la Guía Legislativa para la aplicación de la Convención ${ }^{65}$, dejando claras las obligaciones de los Estados, sobre todo, al momento de realizar las tipificaciones particulares que serán incluidas en sus sistemas penales. No obstante, también se advierte que los legisladores de los Estados no deben centrarse literalmente en la Convención, sino que, por el contrario, deben continuar con la tradición jurídica principios y leyes fundamentales, para evitar el riesgo de la incertidumbre jurídica por parte de los jueces ${ }^{66}$.

El problema jurídico es entonces ¿Cómo armonizar la escala jurídica nacional respecto al fenómeno global? Lo que se sostiene en este trabajo, en la misma línea de Matus, es que es necesario incluir los tipos penales de los principales delitos que forman el delito transnacional, con el fin de que existiendo colaboración y operando herramientas como la extradición las autoridades puedan sancionar a los criminales. Además, es necesario que en materia penal ${ }^{67}$ los Estados: primero, tipifiquen ciertos delitos de manera conjunta; segundo, establezcan medidas efectivas para la responsabilidad de personas jurídicas en la comisión de delitos; tercero, adopten reglas que favorezcan la delación de redes. Y en materia procesal ${ }^{68}$, es necesario que: primero, tomen medidas para aumentar la efectividad de la persecución y el castigo en el ámbito interno (como la inteligencia); segundo, adopten medias procesales y administrativas de los paraísos o refugios criminales, tales como el levantamiento del secreto bancario; tercero, reglas de jurisdicción compartida entre Estados; y, cuarto, regulaciones sobre procesos de extradición para facilitarlos o en caso de una negativa, permitir el enjuiciamiento en el país de la comisión del delito.

Otro de los elementos que plantea la Guía Legislativa es sobre la penalización de la conducta por participar en un grupo delictivo transnacional, la cual debe contener unos requisitos específicos de carácter externo que se establecen entre los numerales 52 y $54^{[69]}$. Estos elementos, son relevantes para los penalistas y criminólogos, dado que configuran "la externalización

64 Ibíd.

65 ONU. Guía legislativa para la aplicación de la Convención de las Naciones Unidas contra la Delincuencia Organizada Transnacional. Nueva York: Naciones Unidas, 2004.

66 Ibíd.

67 Ibíd.,p. 277.

68 Ibíd.,p. 278.

69 ONU. Guía legislativa para la aplicación de la Convención de las Naciones Unidas contra la Delincuencia Organizada Transnacional. Nueva York: Naciones Unidas, 2004, pp. 19-20. 
de la conducta humana" ${ }^{\text {" }}$. Su objetivo es que puedan aplicarse las diversas legislaciones, pues al tratarse de delitos transnacionales la aplicación de la ley se define por el factor territorial, y evitar lo que ha sucedido en muchos casos en los que los criminales son capturados en un país en el que las conductas realizadas no se ajustan a los tipos penales y por tanto no existe el delito.

Frente a esta dificultad, se considera, de acuerdo con Matus, que es necesaria la eliminación de las conductas volitivas en el tipo, de la clase "con el propósito de" (traficar) y "a sabiendas de" (el origen ilícito de un objeto), dado que estos elementos subjetivos exigen al juzgador llegar a conocer la intención criminal. Y como se ha analizado, en el delito transnacional basta con que los elementos objetivos del tipo permitan inferir las intenciones del autor o los autores criminales ${ }^{71}$. En este sentido Matus señala, desde una perspectiva del Derecho Internacional, que las consideraciones subjetivas son conceptos abolidos en la ciencia penal contemporánea; en la interpretación de los tratados, quien realiza la labor hermenéutica no puede atenerse a la voluntad de las naciones, más allá de lo que las cláusulas consagran. Extendiendo este razonamiento a un Derecho Penal Transnacional por fuera de Europa, no sería productivo incorporar elementos subjetivos al tipo que colocaran al fallador frente a la deliberación sobre algunas figuras como el dolo eventual o la preterintención.

Otro aspecto relevante de la situación del derecho frente al сот es la necesidad de considerar más allá de la criminalización, la posibilidad real de intervenir sobre los resultados económicos del delito. En el mundo contemporáneo, donde se discuten asuntos como la abolición del delito y la abolición de las penas, aparece en el primer renglón de las medidas sancionatorias la confiscación y la extinción del dominio sobre los bienes obtenidos a través de medios criminales. No hay nada más contundente para afectar a las redes del delito transnacional que atacar sus fuentes de financiamiento. Con los nuevos enfoques criminales, la confesión de los delitos, la incriminación a los coautores del delito y a sus beneficiarios, los delincuentes reducen las penas drásticamente, son recluidos por unos años, luego de los cuales, recobran la libertad y pueden usufructuar los bienes obtenidos, sin limitaciones. He ahí la debilidad que deben atacar los Estados.

\section{CONCLUSIONES}

En la crisis del Estado nación se presentan muchos componentes, como en cualquier cambio radical del paradigma social, por lo que, también hay que decir que es una de las consecuencias de las transformaciones culturales,

70 Matus, J. La política criminal de los tratados internacionales. Ius et Praxis, 13 (1), 267-289, 2007, 279.

71 Ibíd. 
políticas y económicas sucedidas en las últimas décadas del siglo xx y las primeras del xxI. El Estado nación fue el eje de articulación de los territorios, el principio ordenador de la institucionalidad y cristalización de la soberanía en el ámbito espacial, como consecuencia de las acciones que condujeron al monopolio del ejercicio del poder y su monopolio. Y en el mundo contemporáneo su crisis se ha fortalecido a partir del cot.

La crisis planteada en este texto fue abordada desde múltiples disciplinas. Esta perspectiva busca abrir el debate sobre los problemas que genera un fenómeno criminal que silencioso se expande por el mundo con una nueva forma de operar en red que supera las jerarquías y procesos de las instituciones. En el caso particular del problema jurídico se evidenció que, a pesar de la existencia de mecanismos jurídicos, la cuestión de fondo pasa por cómo armonizar las escalas nacionales frente al fenómeno global. Es decir, cómo los Estados pueden romper sus límites territoriales determinados por la soberanía, jurisdicción y competencia garantizando la eficacia de la norma.

Las respuestas de los Estados en el contexto internacional siguen un ideal de cooperación que termina limitada por la esfera nacional. Sin embargo, cuando se observa el panorama general aparece otra pregunta: ¿qué están haciendo las autoridades de los Estados para combatir el сот? De acuerdo con la interpretación aquí planteada, es que parece que el crimen anda suelto mientras que el Estado sigue amarrado a su territorialidad. Bajo este orden de ideas se pudo evidenciar que el problema no es de normas sino de capacidades al momento de aplicarlas. La crisis del Estado nación sigue siendo territorial y se enfrenta a fenómenos globales.

Por lo anterior es que se concluye que es necesario también una salida política y esta se entiende como una redefinición de la soberanía, que aquí fue planteada como fragmentación. Bajo este orden de ideas, los Estados deben explorar formas de soberanía compartida que conlleven a una hibridación del derecho y de los organismos de justicia y seguridad.

Aunque no es desarrollado a profundidad, se concluye que en la vía de la hibridación del Estado y su soberanía es necesario que estos vayan más allá de la pena y se tomen medidas sancionatorias de confiscación y extinción del dominio. Sin embargo, no solo es atacar el financiamiento del delito transnacional, también es necesario establecer obligaciones reales de coordinación operativa, análisis conjuntos e intercambios de experiencias. Pero como se planteaba arriba, es fundamental deconstruir los instrumentos judiciales y los conceptos de jurisdicción y competencia para que efectivamente se sancionen estas conductas.

\section{REFERENCIAS}

Alonso, P., y Ruiz, N., Alvarino, J. Apuntes del tipo penal concierto para delinquir en la legislación colombiana. Pensamiento Americano, 2013, 61-69. 
BARRAS, R. El crimen organizado transnacional: mecanismos de lucha previstos en la estrategia de seguridad nacional 2013. UNISCI Discussion Papers (35), 2014, 279-301.

Blanco, I., y SÁnchez, I. Principales instrumentos internacionales (de Naciones Unidas y la Unión Europea) relativos al crimen organizado: la definición de la participación en una organización criminal y los problemas de aplicación de la ley penal en el espacio. Revista Penal, s.f., 3-14.

Boister, N. Transnational Criminal Law? EJIL, 14 (5), 2003, 953-976.

Callegari, A. Crimen organizado y su tipificación delante del contexto de la expansión del derecho penal. Derecho Penal y Criminología, 31 (91), 2010, 15-39.

Castells, M. La era de la información: economía, sociedad y cultura. Vol. I: La Sociedad Red. México: Siglo xxı, 2006.

Castells, M. La era de la información: economía sociedad y cultura. Vol. III: Fin del Milenio. México: Siglo XII de España Editores, 2006.

Снават, J. El Estado y el crimen organizado trasnacional: amenaza global, respuestas nacionales. Istor: Revista de historia internacional (42), 2010, 3-14.

Chevallier, J. El Estado posmoderno. Bogotá: Universidad Externado de Colombia, 2011.

De Sousa Santos, B. Sociología jurídica crítica. Para un nuevo sentido común en el derecho. Bogotá: Instituto Latinoamericano de Servicios Legales Alternativos, 2009.

Ferrajoli, L. Criminalidad y Globalización. Estudios de Derecho, 65 (145), 2009, 16-29.

Gallagher, A. Trafficking, smuggling and human rights: tricks and treaties. Forced Migration Review (12), 2002, 25-28.

Glenny, M. McMafia: El crimen sin fronteras. Barcelona: Destino, 2009.

Jiménez, C. La lucha de la ue contra el actual crimen organizado: un reto esencial... pero difícil. СІDОв d'Afers Internacionals (111), 2015, 35-56.

JimÉNEZ, O., y CASTRO, L. La criminalidad organizada en la Unión Europea: estado de la cuestión y respuestas institucionales. Revista СIDOB d'Afers Internacionals (91), 2010.

Konrad Adenauer. Seguridad y crimen organizado transnacional. Guatemala: Serviprensa, 2011.

Matus, J. La Política Criminal de los Tratados Internacionales. Ius et Praxis, 13 (1), 2007, 267-289.

Matus, J. Las formas de responsabilidad criminal por el hecho colectivo en el Derecho Internacional y en el derecho interno chileno. Política Criminal, 8 (16), 2013, 363-385.

Mesa, M. Paz y conflictos en el siglo XXI: tendencias globales. Madrid: Icaria, 2007.

MüNKLER, H. Viejas y nuevas guerras. Asimetría y privatización de la violencia. (C. Ramírez, Trad.) Madrid: Siglo XII de España Editores, 2005. 
ONu. Convención de las Naciones Unidas contra la Delincuencia Transnacional y sus Protocolos. Nueva York: Organización de Naciones Unidas, 2004.

onu. Guía legislativa para la aplicación de la Convención de las Naciones Unidas contra la Delincuencia Organizada Transnacional. Nueva York: Naciones Unidas, 2004.

Piedrahita, P. El crimen organizado transnacional como crisis del estado nación, 2017. Disponible en http://purl.org/dc/dcmitype/Text, Universidad Alfonso X el Sabio. https:// dialnet.unirioja.es/servlet/tesis?codigo $=219767$

RESA, C. Crimen organizado transnacional: definición, causas y consecuencias. Madrid: Universidad Autónoma de Madrid, s.f.

Tilly, Ch. Coerción, capital y los Estados Europeos 990-1990. Madrid: Alianza, 1992.

Tolle, A. Las nuevas formas del crimen organizado. Nuevos grupos de delincuencia organizada en el contex to europeo. Revista Catalana de Seguretat Pública (3), 1998, 111-126.

VeIga, F. El desequilibrio como orden. Una historia de la posguerra fría 1990-2008. Madrid: Alianza, 2009.

Weber, M. El político y el científico. México: Ediciones Coyoacán, 2010.

Williams, P. Redes transnacionales de delincuencia. En J. Arquilla y D. Ronfeldt, Redes y guerras en red. El futuro del terrorismo, el crimen organizado y el activismo político. Madrid: Alianza Editorial, 2003.

ZAFFARONI, R. Globalización y crimen organizado. Voces para la libertad. Reflexiones sobre la represión (pp. 261-286). Guadalajara: Universidad Autónoma Metropolitana, 2007.

ZuÑIGA, L. El concepto de criminalidad organizada transnacional: problemas y propuestas. Nuevo Foro Penal, 12 (86), 2016: 62-114. 